\title{
The performance of wastewater treatment by two-species immobilized lignin-degrading mycelial pellet GX-1310
}

\author{
Gaijuan GUO, Wei GUO, Xia DU, Qie FENG, Jinda LI, Hong YAN ${ }^{\dagger}$ \\ College of Chemical and Environmental Engineering, Harbin University of Science and Technology, Harbin, China
}

\begin{abstract}
This study found a new type of immobilized mycelial pellet GX-1310, which can better treat industrial wastewater. Among them, Aspergillus fumigatus G-13 (degradable lignin) was combined with Bacillus cereus X10-1-2 (having the ability to produce cellulase), and the two synergistically produce strong degradation ability. Taking combined mycelial pellet as the research object, its ability to treat papermaking wastewater, heavy metal wastewater and dye wastewater was investigated. The combined mycelial pellet was superior to the single fungal mycelium in the degradation of lignocellulose, removal of heavy metal ions and adsorption capacity of dyes. And the combined mycelial pellet has a wide range of application conditions (temperature range $28-34^{\circ} \mathrm{C}$ and $\mathrm{pH}$ range $4-8$ ), which can maintain high processing capacity for papermaking wastewater, heavy metal wastewater and dye wastewater. After three batches of wastewater treatment, the combined mycelial pellet still maintains high activity and can continuously treat wastewater. The study fixed the single fungal mycelium together with cellulose-degrading bacteria, the strains producing different enzymes were combined to form a multi-functional combined mycelial pellet. This method provides a new way for industrial wastewater treatment.
\end{abstract}

Keywords: Dye, Heavy metal ions, Immobilized mycelial pellet, Lignin, Wastewater treatment

\section{Introduction}

A large amount of waste water and waste liquid are produced in the industrial production process, which is various in variety and complex in composition, and most industrial wastewater contains harmful toxic substances [1]. There are approximately 8.9 $\times 10^{5}$ tons of dye wastewater produced every year and the number of papermaking wastewater is over $2.7 \times 10^{10}$ tons [2]. Japan's Minamata disease and bone pain events are important warnings for humans' neglect of industrial wastewater. For serious water pollution problems, wastewater treatment around the world is facing environmental, economic and political challenges. At present, wastewater treatment mainly includes physical methods, chemical methods and biological methods. With the increasing difficulty in the treatment of industrial wastewater, treatment of wastewater by physical or chemical methods alone is not suitable for the treatment of all current wastewater. For wastewater with complex composition, it usually contains refractory organic substances and toxic substances. Microbial method is usually used to treat these wastewater, which not only can effectively treat these industrial waste- waters, but also can greatly reduce the treatment cost of industrial wastewater [3, 4].

Fungi in submerged culture often grow in the form of compact spherical masses of mycelium known as pellets [5]. And it has the characteristics of not only strong metabolites ability and adsorption capacity of pollutants, but also has good biological activity, fast sedimentation rate and easy solid-liquid separation [6]. In recent years, mycelial pellet have been widely used as biosorbents in industrial wastewater treatment. Fujita et al. [7] have demonstrated that mycelial pellets formed by Aspergillus niger have good starch decomposition ability and TOC removal ability (more than $90 \%$ and $75 \%$, respectively). In a continuously operating bioreactor, the selenite $\left(\mathrm{SeO}_{3}{ }^{2-}\right)$ in the synthetic wastewater is removed using a fungal bioreactor system containing Phanerochaete chrysosporium pellets [8]. Dong et al. [9] investigated the immobilizing fermentation characteristics and o-chlorophenol biodegradation of Rhodopseudomonas palustris using mycelial pellets as a biomass carrier.

However, the mycelial pellets prepared by a single strain still have limitations such as lower efficiency and single function, and
This is an Open Access article distributed under the terms of the Creative Commons Attribution Non-Commercial License (http://creativecommons.org/licenses/by-nc/3.0/) which permits unrestricted non-commercial use, distribution, and reproduction in any medium, provided the original work is properly cited.

Copyright (C) 2021 Korean Society of Environmental Engineers
Received May 21, 2020 Accepted September 06, 2020

${ }^{\dagger}$ Corresponding author

Email: yanhong204821@aliyun.com

Tel: +86-451-86392720 Fax: +86-451-86392708

ORCID: 0000-0002-9550-8311 
the like. Therefore, in order to improve the degradation efficiency of refractory organic compounds and toxic pollutants, studies have focused on two or more kinds of fixed mycelium particles [10, 11]. Zhang et al. [12] studied the biological removal efficiency in the styrene butadiene rubber with combined mycelial pellet (Mycelial pellet of Aspergillus niger Y3 and Acinetobacter calcoaceticus JH-9). Louise and Geoffrey evaluated the biosorption of uranium (90\%, 62\%), strontium (44\%, 39\%) and caesium (41\%, 50\%) by pelleted mycelium of two species of fungi, Rhizopus arrhizus and Penicillium chrysogenum and immobilized Saccharomyces cerevisiae was evaluated in both batch and continuous flow systems [13]. Lin Fanyu et al. [14] used marine xylose lysine Bacillus JZ008 to adsorb heavy metals $\mathrm{Cd}^{2+}$ (95.6\%), $\mathrm{Cr}^{3+}(96.4 \%)$ and $\mathrm{Cu}^{2+}(87.0 \%)$ after 20 d. Lin et al. [15] used Aspergillus fumigatus (L-3) isolated from the soil as an immobilization carrier to immobilize Bacillus licheniformis to form an immobilized system, and studied its degradation efficiency for Congo red. And the study showed that its degradation efficiency can reach more than 99\%. Based on the screening of two marine fungi with lignocellulose degradation ability in the laboratory by Chen et al., a new type of two-strain immobilization system-immobilized mycelium pellets was constructed and used in papermaking wastewater. According to research, the immobilized mycelial pellet not only has a degrading efficiency of nearly 99\% for papermaking wastewater. Moreover, the decolorization rate of Azure Blue B reached 69.7\%, which was 1.6 times that of a single mycelium [16]. However, there are few preliminary studies on the immobilization of bacteria by fungi to form composite mycelial pellets and the treatment of papermaking wastewater.

In this paper, a mycelium pellet was prepared with mixture of a lignin-degrading Aspergillus acting as a biological carrier and $B$. cereus that possesses the ability of cellulose degradation. The ability of cellulose and lignin degradation of the compound mycelium pellet GX-1310 was evaluated. The effects of treatment conditions (temperature, $\mathrm{pH}$, incubation time) in papermaking wastewater, heavy metal wastewater, and dye wastewater were systematically studied, to provide more technology choices for the various industry wastewater treatments [17].

\section{Materials and Methods}

\subsection{Strain Sources}

Aspergillus fumigatus G-13, which could degrade lignin used in this work was isolated from the samples collected from soil near the sewage draining exit of a paper mill in Harbin, China. Strain G-13 was identified as $A$. fumigatus by 18 srDNA sequence analysis. The sequence is shown in the appendix.

Bacillus cereus X10-1-2 was isolated from the local soil by the laboratory of Green Chemical Technology of College of Helongiiang Province. The minimal medium contained (per liter): $\mathrm{Na}_{2} \mathrm{HPO}_{4}$ 3.0 g, $\mathrm{MgSO}_{4} \cdot 7 \mathrm{H}_{2} \mathrm{O} 0.5 \mathrm{~g}, \mathrm{CaCl}_{2} 0.5 \mathrm{~g}, \mathrm{MnSO}_{4} \cdot 7 \mathrm{H}_{2} \mathrm{O} 2.5 \mathrm{mg}, \mathrm{ZnSO}_{4}$ $2.0 \mathrm{mg}, \mathrm{CoCl}_{2} 3.0 \mathrm{mg}$, and $\mathrm{FeSO}_{4} \cdot 7 \mathrm{H}_{2} \mathrm{O} 7.5 \mathrm{mg}$. Wheat bran (30 $\mathrm{g} / \mathrm{L})$ and bean cake (10 g/L) were added to supplement the minimal medium as the carbon source and nitrogen source for maximum cellulase production (unpublished date). After the bacteria were cultured in agarslantculture-medium at $30^{\circ} \mathrm{C}$ for $60 \mathrm{~h}$, the $\mathrm{B}$. cereus
$\mathrm{X} 10-1-2$ was transferred to $4^{\circ} \mathrm{C}$ for storage.

\subsection{Culture Medium}

Mycelium pellet culture medium is made by sucrose $18 \mathrm{~g} / \mathrm{L}$, ammonium tartrate $2.5 \mathrm{~g} / \mathrm{L}, \mathrm{KH}_{2} \mathrm{PO}_{4} 2 \mathrm{~g} / \mathrm{L}, \mathrm{MgSO}_{4} \cdot 7 \mathrm{H}_{2} \mathrm{O} 2 \mathrm{~g} / \mathrm{L}$ in $1 \mathrm{~L}$ of distilled-deionized water (adjust $\mathrm{pH}$ to 5 , autoclave under $120^{\circ} \mathrm{C}$ for $20 \mathrm{~min}$ ).

Culture collection of bacteria is made by beef paste $5 \mathrm{~g} / \mathrm{L}$, peptone $10 \mathrm{~g} / \mathrm{L}, \mathrm{NaCl} 5 \mathrm{~g} / \mathrm{L}$, agar18 g/L in $1 \mathrm{~L}$ of distilled-deionized water (adjust $\mathrm{pH}$ to $7.2-7.4$, autoclave under $120{ }^{\circ} \mathrm{C}$ for $20 \mathrm{~min}$.)

\subsection{Simulated Industrial Wastewater}

Simulated papermaking wastewater is prepared by straw $100 \mathrm{~g}$ (dry weight), $\mathrm{NaOH} 20 \mathrm{~g}$, anthraquinone $0.5 \mathrm{~g}, \mathrm{Na}_{2} \mathrm{~S} 0.795 \mathrm{~g}$, in $580 \mathrm{~mL}$ of distilled-deionized water (heat up to $125^{\circ} \mathrm{C}$ and insulate for $20 \mathrm{~min}$ ).

Simulated heavy mental wastewater is prepared by $\mathrm{CuSO}_{4} 79.93$ mg or $\mathrm{Pb}\left(\mathrm{NO}_{3}\right)_{2} 195.32 \mathrm{mg}$ in $1 \mathrm{~L}$ of distilled-deionized water (autoclave under $120^{\circ} \mathrm{C}$ for $20 \mathrm{~min}$ ).

Simulated dye wastewater is prepared by congo red $100 \mathrm{mg}$, malachite green $100 \mathrm{mg}$, and crystal violet $100 \mathrm{mg}$, respectively, in $1 \mathrm{~L}$ of distilled-deionized water (autoclave under $120^{\circ} \mathrm{C}$ for 20 $\min )$.

\subsection{Preparation of Fungal or Bacterial Suspension}

Colonies of Aspergillus and B. cereus were collected from inclined medium, and then added with normal saline, the concentration of which was $1 \times 10^{6} / \mathrm{mL}$ and $5 \times 10^{6} / \mathrm{mL}$, respectively, and stored at $4^{\circ} \mathrm{C}$.

\subsection{Preparation of Mycelial Pellet}

\subsubsection{Preparation of mycelial pellet of single fungi}

Took $5 \mathrm{~mL}$ of $A$. fumigatus $\mathrm{G}-13$ suspension into the optimized spheroidized culture medium (The carbon source is $18 \mathrm{~g} / \mathrm{L}$ sucrose, the nitrogen source is $2.5 \mathrm{~g} / \mathrm{L}$ ammonium tartrate, and initial $\mathrm{pH}$ of the medium is 5). The culture temperature was $30^{\circ} \mathrm{C}$, the oscillator speed was $160 \mathrm{r} / \mathrm{min}$, and the culture was carried out for $72 \mathrm{~h}$. Under these conditions, the average diameter of mycelial pellet was the largest, about $3.4 \mathrm{~mm}$. The mycelial pellet at this time has a smooth surface and good elasticity, and is suitable as a bio-immobilized carrier. Collected the mycelial pellets by filtration and placed in sterile physiological saline for use.

\subsubsection{Preparation of combined mycelial pellets}

The inoculation amount of $B$. cereus X10-1-2 is $20 \mathrm{~mL}(100 \mathrm{~mL}$ medium), the $\mathrm{pH}$ of medium is 5 , the shaking speed is $160 \mathrm{r} / \mathrm{min}$, and the temperature is $28^{\circ} \mathrm{C}$. Under these conditions, X10-1-2 and G-13 have the best complementarity in the co-fixation process. The two-species immobilization mycelial pellet play a synergistic role in enzyme production process, promoting the secretion of lignin degrading enzymes, cellulase and hemicellulase. Took 5 $\mathrm{mL}$ of G-13 suspension and $20 \mathrm{~mL}$ of X10-1-2 suspension into the optimized spheroidized culture medium. The culture temperature was $30{ }^{\circ} \mathrm{C}$, the oscillator speed was $160 \mathrm{r} / \mathrm{min}$, and cultivated for $72 \mathrm{~h}$. Collected the mycelial pellets by filtration and placed in sterile physiological saline for use. 


\subsection{Papermaking Wastewater Treatment Experiments}

Took $0.1 \mathrm{~g}$ of the sample to be tested, added $5 \mathrm{~mL}$ of acetic acid-nitric acid mixed solution $\left(10 \mathrm{~mL}\right.$ of concentrated $\mathrm{HNO}_{3}$ and $100 \mathrm{~mL}$ of $80 \%$ acetic acid), heated in a boiling water bath for $20 \mathrm{~min}$, cool and filter. Took $1 \mathrm{~mL}$ of the filtrate, added $4 \mathrm{~mL}$ of lichenol reagent, held at $100^{\circ} \mathrm{C}$ for $15 \mathrm{~min}$, and measured the OD value at $660 \mathrm{~nm}$. According to the standard curve of xylose, the amount of sugar was calculated, and then multiplied by a coefficient of 0.9 , which was the content of hemicellulose. The filter residue was washed twice with acetone, dried to constant weight at $60^{\circ} \mathrm{C}$, placed in a beaker, added with $5 \mathrm{~mL}$ of $72 \%$ sulfuric acid, hydrolyzed at $20^{\circ} \mathrm{C}$ for $3 \mathrm{~h}$, added with water $45 \mathrm{~mL}$, stayed overnight at room temperature and filter the next day. Took $2 \mathrm{~mL}$ of the filtrate, added $5 \mathrm{~mL}$ of anthrone reagent, held at $100^{\circ} \mathrm{C}$ for $10 \mathrm{~min}$, and measured the $\mathrm{OD}$ value at $660 \mathrm{~nm}$. According to the standard curve of glucose, the amount of sugar was calculated, and then multiplied by a coefficient of 0.9 , which was the content of cellulose. The residue obtained by filtration was dried to constant weight at $80^{\circ} \mathrm{C}$, weighed and then ashed at $550^{\circ} \mathrm{C}$, the obtained mass was lignin content [18].

Mixed suspension $5 \mathrm{~mL}$ was inoculated on $100 \mathrm{~mL}$ of the 1:4 dilution of simulation papermaking wastewater after sterilized (160 $\mathrm{r} / \mathrm{min}$ and $28^{\circ} \mathrm{C}$ ). In contrast, the control group was not treated by mycelial pellet under the same conditions. Regularly samples and analysis the lignocellulose content in the culture. To determine the lignocellulose degradation ability of two-species immobilized mycelial pellet, the contents of lignin, cellulose, and hemicellulose were analyzed.

Degradation efficiencies of lignin, cellulose or hemicellulose at the nth day $\left(D_{n}\right)$ were calculated by the following formula:

$$
D n=\frac{m_{p}-m_{n}}{m_{p}} \times 100 \%
$$

Where $m_{p}$ and $m_{n}$ represent the total amount of lignin, cellulose or hemicellulose in fermentation substrate at the previous sampling time and that at the nth day (DR), respectively.

\subsection{Simulated Heavy Metal Wastewater Treatment Experiments}

$5 \mathrm{~mL}$ of the mixed suspension was inoculated into $250 \mathrm{~mL}$ Erlenmeyer flask containing $100 \mathrm{~mL}$ of simulated heavy metal waste water. Cultured in an oscillator at $28^{\circ} \mathrm{C}$ and $160 \mathrm{r} / \mathrm{min}$ and sampled regularly. The supernatant (centrifugated at 6,000 r/min for 10 min) was collected for determine $\mathrm{Cu}^{2+}$ or $\mathrm{Pb}^{2+}$ concentration. The concentrations of $\mathrm{Cu}^{2+}$ and $\mathrm{Pb}^{2+}$ were determined by atomic absorption spectrophotometry. All the experiments were performed in triplicate.

The removal efficiency of $\mathrm{Cu}^{2+}$ and $\mathrm{Pb}^{2+}$ at the nth day $\left(\mathrm{M}_{\mathrm{n}}\right)$ was calculated by the following formula:

$$
M n=\frac{m_{p}-m_{n}}{m_{p}} \times 100 \%
$$

Where $\mathrm{C}_{\mathrm{p}}$ and $\mathrm{C}_{\mathrm{n}}$ represent the content of $\mathrm{Cu}^{2+}$ and $\mathrm{Pb}^{2+}$ at the previous sampling time and that at the nth day, respectively.

\subsection{Dye Wastewater Treatment Experiments}

$5 \mathrm{~mL}$ of the mixed suspension was inoculated into $250 \mathrm{~mL}$ Erlenmeyer flask containing $100 \mathrm{~mL}$ of dye culture solution. The control group was cultured under the same conditions (without mixed suspension) [19]. Cultured in an oscillator at $28^{\circ} \mathrm{C}$ and 160 $\mathrm{r} / \mathrm{min}$ and sampled regularly. The supernatant was collected (centrifuged at 6,000 r/min for $10 \mathrm{~min}$ ) and absorbance at the maximum absorption wavelength of each dye was measured with an ultraviolet-visible spectrophotometer. The absorbance of the dye culture solution which was not inoculated with the hyphae sphere was used as a control, and calculated the decolorization rate. All the experiments were performed in triplicate. The dye decolorization rate $\left(\mathrm{C}_{\mathrm{n}}\right)$ calculated by the following equation:

$$
C n=\frac{a_{p}-a_{n}}{a_{p}} \times 100 \%
$$

Where $a_{p}$ is the dye absorbance of the control and $a_{n}$ is the dye absorbance of the samples.

\section{Results and Discussion}

\subsection{Morphology of Combined Mycelial Pellets}

Fig. 1 (a) is a combined mycelial pellet formed under the optimum balling conditions screened by previous experiments. The formed mycelial pellet is white, uniform in size (average diameter of about $4.35 \mathrm{~mm}$ ), smooth in surface and has certain mechanical strength. Fig. 1 (b) shows the internal structure observed by scanning electron microscopy after cutting the mycelial pellet. The large number of interlaced filaments seen in Fig. 1 (b) are hyphae produced by Aspergillus fumigatus. Because the bacteria of Bacillus cereus used in this study are rod-shaped, the size is $1-1.2^{*} 3-5 \mu \mathrm{m}$, at this magnification, we can see a large number of small bright spots on the hyphae that are the bacteria of Bacillus. As shown in the SEM images, a large number of bacteria were found in the inner space of mycelial pellet, X10-1-2 bacteria were successfully immobilized on the G-13 mycelia, suggesting that the pellet's polyporous structure provides sufficient surface area for the adhesion of X10-1-2 bacteria and to establish a microecological environment suitable for bacterial growth [20]. The mycelial pellet is formed by winding mycelium, and has a spatial network structure inside, which has the characteristics of porous and large surface area. It indicates that the combined mycelial pellet can be used as a biomass carrier to meet the needs of treating wastewater.

\subsection{Capability Comparison between the Single-strain Mycelial Pellet and Two-species Immobilized Mycelial Pellet GX-1310}

$5 \mathrm{~g}$ of single-strain mycelial pellet and $5 \mathrm{~g}$ of two-species immobilization mycelial pellet were respectively introduced into simulated papermaking wastewater, dye wastewater and heavy wastewater. Table S1 shows the difference in degradation efficiency between the single-strain and two-species immobilization mycelial pellet GX-1310 under the same culture conditions. Generally, the processing efficiency does appear significantly different. The combined 


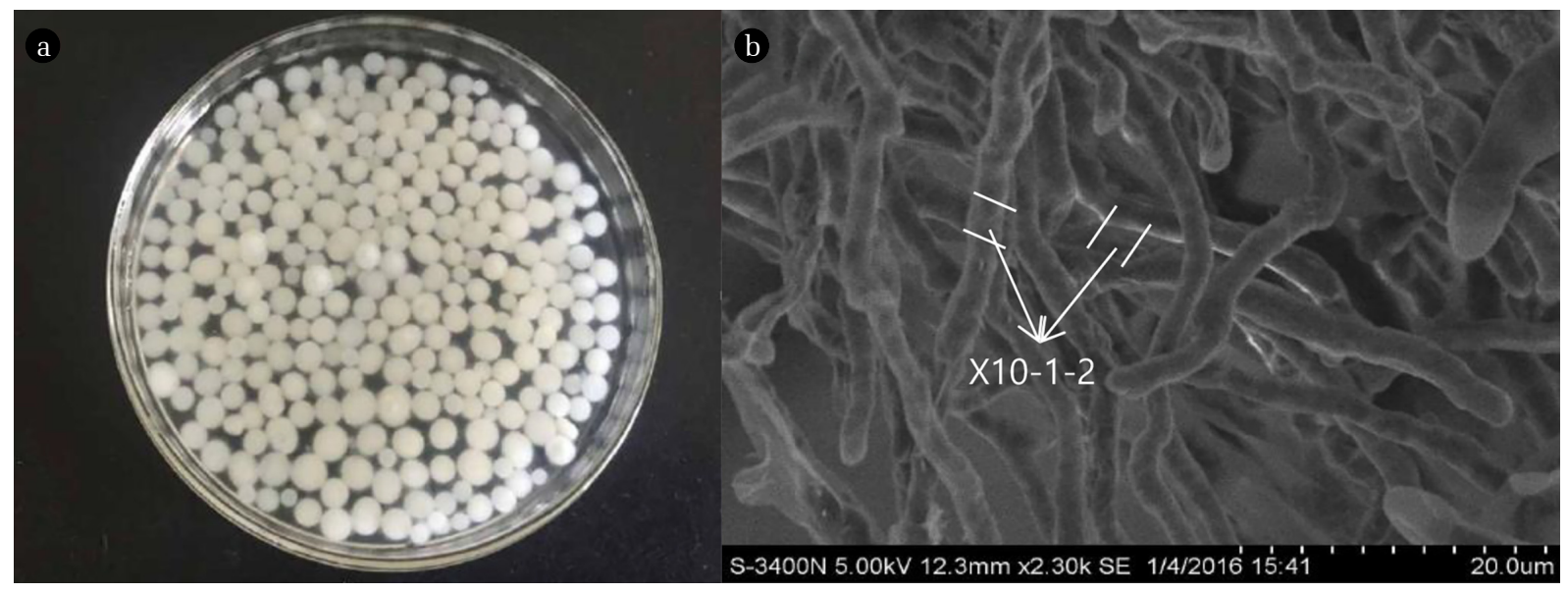

Fig. 1. Appearance shape of combined mycelial pellet (a) and Scanning electron micrograph of mycelial pellet (b). Scale bar $=20 \mu \mathrm{m}$.

Mycelial Pellets are better for treatment of papermaking wastewater. The degradation rate of lignin (L) increased by more than $10 \%$, and the degradation rate of cellulose (C) and hemicellulose $(\mathrm{H})$ increased by more than $30 \%$. This is due to the fact that mycelial pellet fixes the $B$. cereus, which confers the ability of the combined mycelial pellets to degrade cellulose and hemicellulose. Compound mycelium plays a synergistic role in the process of enzyme production, thereby increasing the degradation rate of lignocellulose. For the treatment of other wastewater, it is first reported in the literature that both Aspergillus fumigatus [21, 22] and Bacillus [23, 24] have adsorption capacity for pollutants (dye wastewater and heavy metal ions). Secondly, their adsorption of pollutants may be a process of biological adsorption [21, 22, 24]. Therefore, the composite mycelium pellets may act through the active sites on the surface during the adsorption process. In addition, biosorption is related to the surface area of the organism. The larger the surface area of the organism, the stronger the adsorption capacity. The interior of the mycelium pellets of Aspergillus fumigatus shows a spatial network structure. With the fixation of Bacillus, the surface area of mycelium pellets increases, so the adsorption capacity of composite mycelium pellets for pollutants is significantly greater than that of single mycelium pellets for pollutants. For the treatment of dye wastewater, the decolorization rates of Congo red (CR), malachite green (MG) and crystal violet (CV) by single fungal mycelium were $69.51 \%, 71.13 \%$ and $62.33 \%$, respectively. The decolorization rates of the above three kinds of dyes by the combined mycelial pellets were $92.74 \%, 91.61 \%$ and $84.23 \%$, respectively. For the adsorption of heavy metal ions, the adsorption rates of $\mathrm{Cu}^{2+}$ and $\mathrm{Pb}^{2+}$ by single fungal mycelium spheres were $38.27 \%$ and $34.06 \%$, respectively. The adsorption rates of $\mathrm{Cu}^{2+}$ and $\mathrm{Pb}^{2+}$ by the combined mycelial pellets were $65.96 \%$ and $52.33 \%$, respectively. It is concluded that the performance of the two-species immobilization mycelial pellet is superior to that of the single-strain mycelial pellet for the degradation and adsorption of various wastewaters.

\subsection{GX-1310 Treatment Experiments of Papermaking Wastewater}

3.3.1. Effect of temperature on degradation of lignocellulose

The water was sampled at an interval of $2 \mathrm{~d}$ and tested the maximum degradation rate of lignocellulose under different temperatures to study the effect of temperature [25]. As elucidated in Fig. 2, the optimum temperature range was $28-34^{\circ} \mathrm{C}$ of GX-1310. Lignin degradation rate got highest at $28^{\circ} \mathrm{C}$ up to $58.01 \%$. However, the degradation rate of cellulose and hemicellulose reached the highest, as high as $45.39 \%$ and $57.45 \%$ when the temperature was $30^{\circ} \mathrm{C}$ and $34^{\circ} \mathrm{C}$, respectively. The degradation rate of the three was $31.53 \%$, $21.55 \%$ and $27.52 \%$ at $24^{\circ} \mathrm{C}$, and even if the temperature raised to $40^{\circ} \mathrm{C}$, degradation rate still reached up to $32.86 \%, 36.09 \%$ and $37.91 \%$. And our previous research found that the composite mycelial pellets have low enzyme activity at low temperatures. When the temperature is $28^{\circ} \mathrm{C}$, the lignin degrading enzyme activity reaches the maximum, and when the temperature is $30^{\circ} \mathrm{C}$, the cellulase activity reaches the maximum. At $34^{\circ} \mathrm{C}$, the hemicellulase activity reaches its maximum [26]. This is because different components are affected by different enzymes, so the required temperature is different. Even if a small number of enzymes have multiple repeated degradation functions, the most suitable temperature for

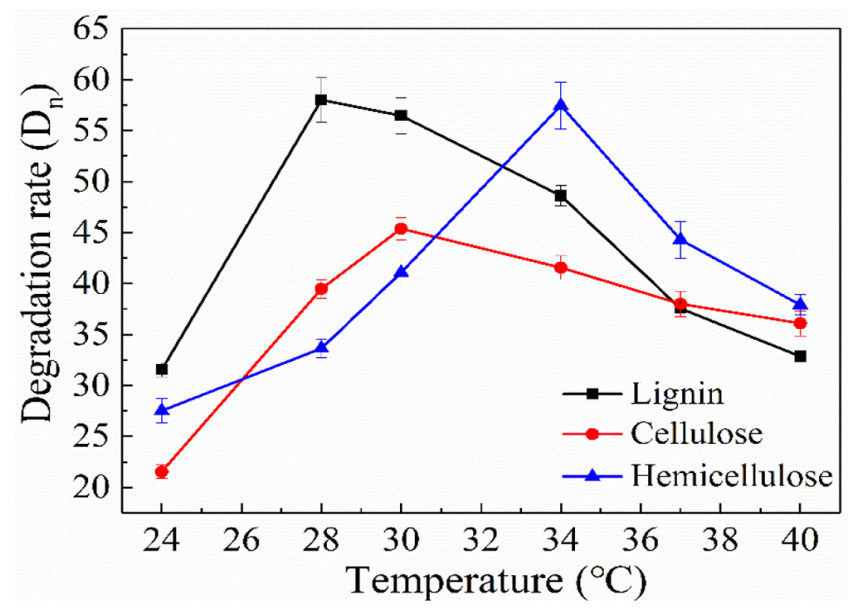

Fig. 2. Effect of temperature on lignin, cellulose and hemicellulose degradation. (The experiment conditions were as follows: 160 $\mathrm{r} / \mathrm{min}$ and $28,30,34,37$ and $40^{\circ} \mathrm{C}$, respectively. Sampled at an interval of 2 days). 
each enzyme is also different. Results show that GX-1310 has good degradation effect on papermaking wastewater in the high temperature environment so as to be applied to a wide range of temperature [27]. Since in the existing literature, no matter whether it is a single bacteria (G-13 or X10-1-2) or a double bacteria (GX-1310), there is no report of papermaking wastewater treatment. We can say that this is the first time to study it. However, this removal efficiency is not very high at present and needs to be further improved.

\subsubsection{Effect of $\mathrm{pH}$ on degradation of lignocellulose}

Degradation of papermaking wastewater can be significantly influenced by initial $\mathrm{pH}$ of solution. As illuminated in Fig. S1, for lignin, the degradation rate was maximum at the initial $\mathrm{pH} 5$, reaching $61.38 \%$, however the data decreased to $14.01 \%$ and $12.09 \%$, respectively in either strong acid or alkali, which shows that the degradation of lignin can be intensely inhibited by strong acid and alkali, and the reason may be that the environment will inhibit the production of lignin-degrading enzymes, which is harmful to the degradation of lignin in papermaking wastewater [28]. Our previous studies have shown that when $\mathrm{pH}$ value is less than 3 or greater than 8 , composite mycelium pellets do not form, indicating that strong acid and strong base inhibit the survival of composite mycelium pellets. It is pelletized and produces enzymatic activity when $\mathrm{pH}$ is between 3 and 7.Under the $\mathrm{pH} 5$ condition, the enzyme activity of composite mycelium pellets was the highest, and the pellet formation state was the best [26]. In addition, it is very coincidental that both Bacillus (X10-1-2) and Aspergillus fumigatus (G-13) produced the highest enzyme activity at pH 5 [29, 30]. This coincidence provides a very favorable condition for the survival of the two bacteria at $\mathrm{pH}$ 5, so that the bacteria can simultaneously exert the ability to produce the highest enzyme activity. But the rates of other two lignocellulose as the initial $\mathrm{pH}$ was increased from 2 to 7, the degradation rate kept increasing, peaked at over $50 \%$, then started to decline. The rate of cellulose and hemicellulose in papermaking wastewater at $\mathrm{pH}$ value from 5 to 11 could be maintained at more than $40 \%$. All these results indicated that even in acidic or alkaline environment, GX-1310 could still keep efficient to treat papermaking wastewater, however lignin degradation capability still need to be improved [31].

\subsubsection{Effect of incubation time on degradation of lignocellulose} As expounded in Fig. 3, GX-1310 degradation rate of lignin showed a rise first followed by a decline with incubation time, as lignin is mainly composed of acid-soluble lignin macromolecules and small molecules of acid insoluble lignin composition. In the beginning, acid soluble part was degraded, the molecular system of lignin fragments gradually decreased, the degradation rate increased gradually and reached the highest at $144 \mathrm{~h}$, was $63.61 \%$. Therefore, in the process of degradation, pellets degraded large molecular fragments of acid-soluble lignin into small molecules of acid insoluble lignin, as a result, the system of acid-insoluble lignin content increased along with lignin degradation rate decreased. GX-1310 also has a very high ability of degradation of cellulose and hemicellulose, the highest degradation rates were $49.05 \%$ at $72 \mathrm{~h}$ and $63.36 \%$ at $60 \mathrm{~h}$, respectively. At $90 \mathrm{~h}$, according to enzyme catalysis kinetics, the enzyme is saturated with substrates. So after $90 \mathrm{~h}$, the degradation efficiency of composite

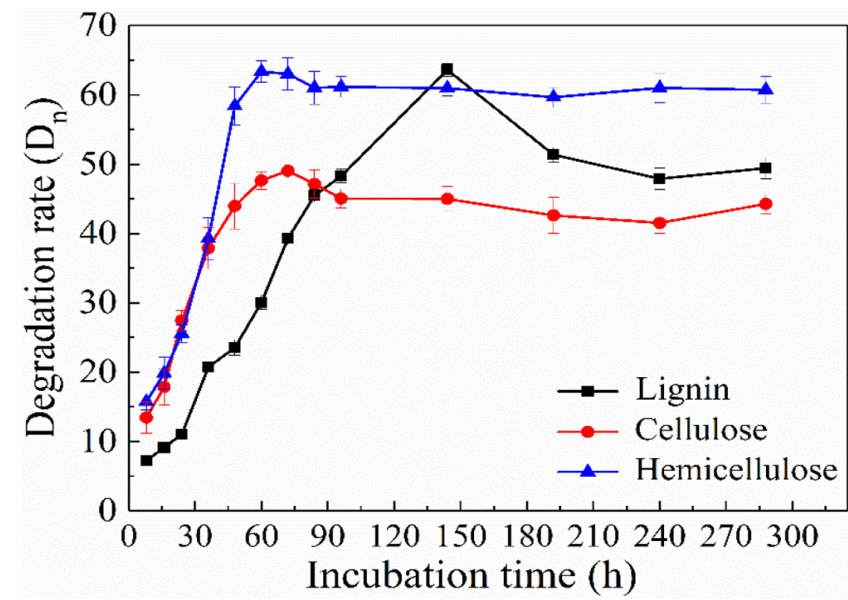

Fig. 3. Effect of incubation time on lignin, cellulose and hemicellulose degradation. (The experiment conditions were as follows: 160 $\mathrm{r} / \mathrm{min}$ and $28^{\circ} \mathrm{C}$. Sampled at an interval of 1 day).

mycelium pellets for cellulose and hemicellulosic tended to be basically stable. Therefore, with the extension of time, the degradation efficiency of cellulose and hemicellulose is stable at about $60 \%$ and about $45 \%$, respectively.

\subsubsection{Effect of recycle on degradation of lignocellulose}

For the investigation of the stability of GX-1310 and its reuse effect, the culture was shocked at $160 \mathrm{r} / \mathrm{min}$ and $28^{\circ} \mathrm{C}$ for $5 \mathrm{~d}$, and this process was repeated four times, the results are shown in Table S2. At the first time, lignocellulose degradation was pretty good, and degradation rates of lignin, cellulose and hemicellulose were $51.27 \%, 41.58 \%, 57.1 \%$ respectively. With the increase of the frequency the fractions of lignocellulose degradation rate decreased, and at the third times, pellet surface was not smooth as originally with the color deepening, then degradation rate dropped gradually. But the degradation rate of all three kinds of lignocellulose could maintain more than $20 \%$. Until the fourth cycle, the mycelium pellet began to appear autolysis phenomenon. The results revealed that GX-1310 can be used three times and retain high activity for long time. This indicates that the combined mycelial pellets could be used repeatedly to treat papermaking wastewater, and the activity could be maintained for a relatively long time.

\subsection{GX-1310 Adsorption Experiments of Heavy Metal Wastewater}

3.4.1. Effect of temperature on adsorption of $\mathrm{Cu}^{2+}$ and $\mathrm{Pb}^{2+}$ Tested the maximum adsorption rate of $\mathrm{Cu}^{2+}$ and $\mathrm{Pb}^{2+}$ under different temperatures. The effects of temperature on the removal rates of heavy metal ions are shown in Fig. 4. [32]. The optimum temperature range was $28-34^{\circ} \mathrm{C}$ which was similar to papermaking wastewater. The percentages of $\mathrm{Cu}^{2+}$ and $\mathrm{Pb}^{2+}$ absorbed raised from approximately $20 \%$ to about $60 \%$ with temperature increasing. The biosorption rates of $\mathrm{Cu}^{2+}$ increased up to $63.73 \%$ at $28^{\circ} \mathrm{C}$, and $\mathrm{Pb}^{2+}$ to $57.83 \%$ at $30^{\circ} \mathrm{C}$, then began to decline. This is because we found in the previous study that under the condition of $28^{\circ} \mathrm{C}$, the compound mycelial pellets are in the best growth state [30, 26]. However, adsorption was less effective at $20^{\circ} \mathrm{C}$ or $40^{\circ} \mathrm{C}$. It 


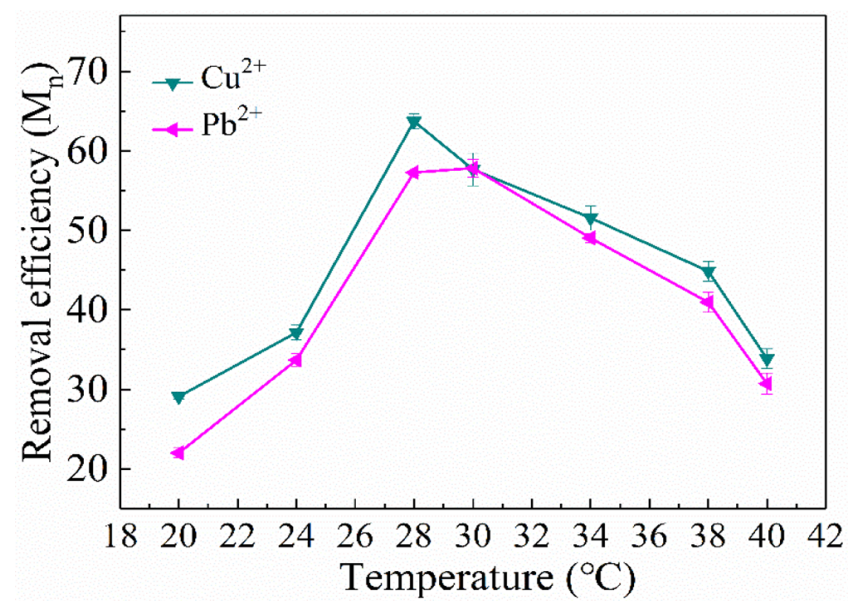

Fig. 4. Effect of temperature on $\mathrm{Cu}^{2+}$ and $\mathrm{Pb}^{2+}$ adsorption. (The experiment conditions were as follows: $160 \mathrm{r} / \mathrm{min}$ and 20, 24, 28, $30,34,37$ and $40^{\circ} \mathrm{C}$, respectively. Sampled at an interval of 1 day).

instructed that temperature can affect the adsorption of heavy metal roughly when the temperature exceeds the threshold temperature.

3.4.2. Effect of $\mathrm{pH}$ on adsorption of $\mathrm{Cu}^{2+}$ and $\mathrm{Pb}^{2+}$

$\mathrm{pH}$ is one of the most important parameters controlling uptake of heavy metals from wastewater. Fig. S2 shows the effect of $\mathrm{pH}$ on $\mathrm{Cu}^{2+}$ and $\mathrm{Pb}^{2+}$ removal efficiencies of compound mycelium pellets. As expected, the adsorptions of $\mathrm{Cu}^{2+}$ and $\mathrm{Pb}^{2+}$ are of high-efficiency in the neutral condition. The percentage adsorption increased with $\mathrm{pH}$ to attain a maximum at $\mathrm{pH} 5$ and thereafter it decreased with further increasing in $\mathrm{pH}$ value. The maximum removal of $\mathrm{Cu}^{2+}$ and $\mathrm{Pb}^{2+}$ at $\mathrm{pH} 5$ were found to be nearly $73.21 \%$ and $59.29 \%$, respectively, which may be attributed to the fact that the proton occupied most of the adsorption sites on the surface of mycelial with lower $\mathrm{pH}$. The adsorption percentage of heavy metal ion was awfully effective with increasing of $\mathrm{pH}$ from 5 to 9 . On the contrary, as the $\mathrm{pH}$ over 9 , the $\mathrm{OH}^{-}$in solution would combine with functional groups on the surface of mycelium pellets, which may be competition with metal ions, and then lead to the adsorption rate decreased. $\mathrm{Cu}^{2+}$ (> $75 \%$ ) was removed more efficiently than $\mathrm{Pb}^{2+}$, and similar results was also reported by Chrysi and Papadimitriou. Moreover, it should be underlined that adsorption of $\mathrm{Pb}^{2+}$ was sensitive to $\mathrm{pH}$ than $\mathrm{Cu}^{2+}$. With $\mathrm{pH}$ increasing to appropriate, the number of $\mathrm{Cu}^{2+}$ doubled while the data of $\mathrm{Pb}^{2+}$ magnified almost three times. The results put on view that this kind of pellet has a good adsorption effect on heavy metal ions in neutral and acidic environment.

3.4.3. Effect of incubation time on adsorption of $\mathrm{Cu}^{2+}$ and $\mathrm{Pb}^{2+}$ The water was sampled at an interval of $30 \mathrm{~min}$ and then tested. The influence of incubation time on the adsorption of metal ions $\left(\mathrm{Cu}^{2+}, \mathrm{Pb}^{2+}\right)$ was studied and results obtained are represented in Fig. 5, adsorption of $\mathrm{Cu}^{2+}$ and $\mathrm{Pb}^{2+}$ achieved 51.27\% and 31.65\%, respectively in a quite short period of time, just in $2 \mathrm{~h}$. The concentration of heavy metal ions decreased rapidly since complexation of active groups with heavy metal ions on the cell wall was quite rapid during this state of surface adsorption. After that, as time

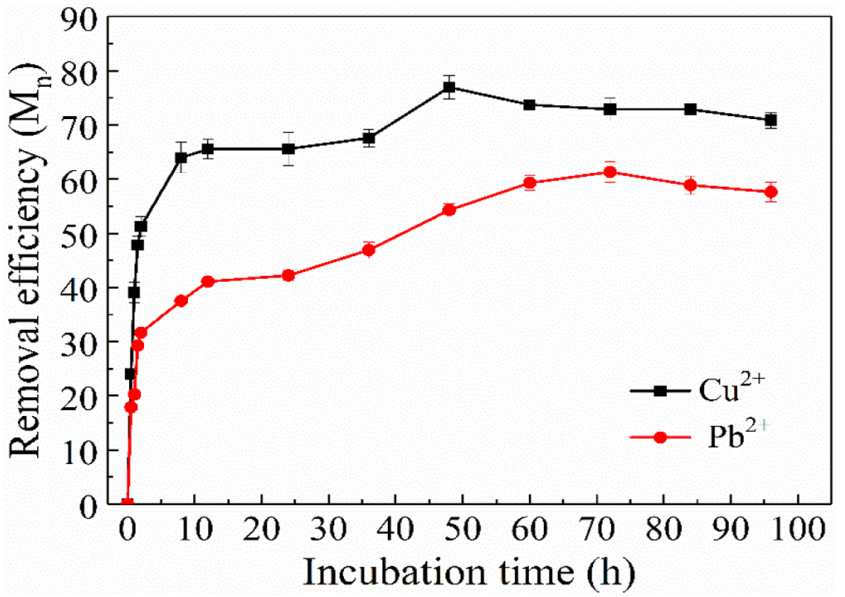

Fig. 5. Effect of incubation time on $\mathrm{Cu}^{2+}$ and $\mathrm{Pb}^{2+}$ adsorption. (The experiment conditions were as follows: $160 \mathrm{r} / \mathrm{min}$ and $28^{\circ} \mathrm{C}$. Sampled at an interval of $0.5 \mathrm{~h}$ ).

increasing, concentration of heavy metal ions in solution decreased slowly until adsorption equilibrium, which could be explained as adsorption of heavy metal ions on the cell wall reached saturation with the increase of adsorption amount, and the resistance would be increased as metal ions entered cells, so that the adsorption reached saturation for a long time. Adsorption rate of $\mathrm{Cu}^{2+}$ and $\mathrm{Pb}^{2+}$ reached the maximum, $76.96 \%$ and $61.32 \%$ in $48 \mathrm{~h}$ and $72 \mathrm{~h}$, respectively.

\subsection{GX-1310 Treatment Experiments of Dye Wastewater}

\subsubsection{Effect of temperature on congo red, malachite green and} crystal violet decolorization

The result of temperature studies for the adsorption of congo red, malachite green and crystal violet at different temperatures are given in Fig. 6, the effect on dye was not significant when the temperature varied from 24 to $34^{\circ} \mathrm{C}$. The reason is that too high $\left(38^{\circ} \mathrm{C}\right)$ or too low temperature $\left(26^{\circ} \mathrm{C}\right)$ can lead to the decrease of biomass. We found that decolorization rate of malachite green and crystal violet was lower than that of congo red. The maximum

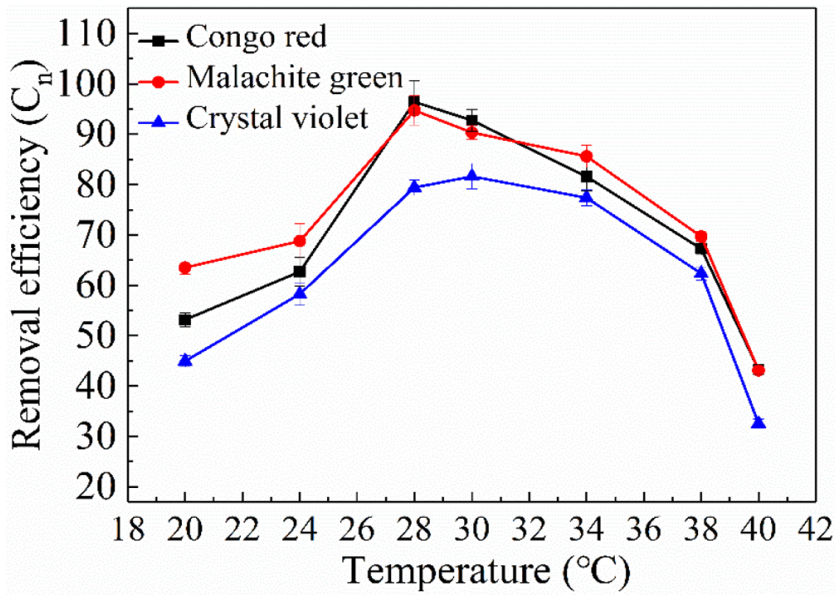

Fig. 6. Effect of temperature on the dye decolorization. (The experiment conditions were as follows: $160 \mathrm{r} / \mathrm{min}$ and 20, 24, 28, 30, 34, 37 and $40^{\circ} \mathrm{C}$, respectively. Sampled at an interval of 1 day). 
malachite green and congo red removal rate reached $94.75 \%$ and $96.43 \%$ at $28^{\circ} \mathrm{C}$. And crystal violet peak as $81.63 \%$ at $30^{\circ} \mathrm{C}$. When the temperature reached $40{ }^{\circ} \mathrm{C}$, decolorization rate of all three dyes was about $30 \%$. It can be inferred that the extreme temperature will reduce decolorization rate of GX-1310.

\subsubsection{Effect of $\mathrm{pH}$ on congo red, malachite green and crystal violet decolorization}

Removal of dyes from aqueous solutions at different $\mathrm{pH}$ and temperatures by GX-1310 has been carried out successfully. As shown in Fig. S3, with increasing of $\mathrm{pH}$ from 2 to 7, the percentage of the dye adsorbed by pellets increased from 55\% to $98 \%$, $30 \%$ to $92 \%$ and $45 \%$ to $70 \%$ for congo red, malachite green and crystal violet, respectively, which shows that removal of pollutants from wastewater by adsorption is greatly influenced by the $\mathrm{pH}$ of solution. By affecting the surface charge of the adsorbent and the extent of ionization, consequently, the rate of adsorption increased [34]. A change of $\mathrm{pH}$ affects the adsorptive process through dissociation of functional groups on the adsorbate and adsorbent. Dyes which ionize to give the colored cationic dye base will undergo attraction approaching the anionic structure of the adsorbents. Decolorization rates of three dyes were as high as $70 \%$ at $\mathrm{pH}$ of $5-9$. The maximum decolorization of congo red and malachite green can reach $97.87 \%$ and $94.55 \%$ at $\mathrm{pH} 5$. While decolorization ability of crystal violet was peaked at $83.67 \%$ at $\mathrm{PH}$ 7. The results show that the adsorption of dyes could be of great efficiency in weak acidic and alkaline system. However, similar to the effect of temperature, congo red is less sensitive to $\mathrm{pH}$ among the three dyes.

\subsubsection{Effect of incubation time on congo red, malachite green and crystal violet decolorization}

As seen in Fig. 7, the adsorption amount of the three kinds of dyes by combined mycelial pellets increased very rapidly within $2 \mathrm{~h}$, and then gradually slowed down until the adsorption equilibrium. For the three dyes of congo red, malachite green and crystal violet dyes, the decolorization rate could reach more than $70 \%$ in the first $12 \mathrm{~h}$, and the decolorization rate was faster. The decolorization of congo red was faster and more efficient at the

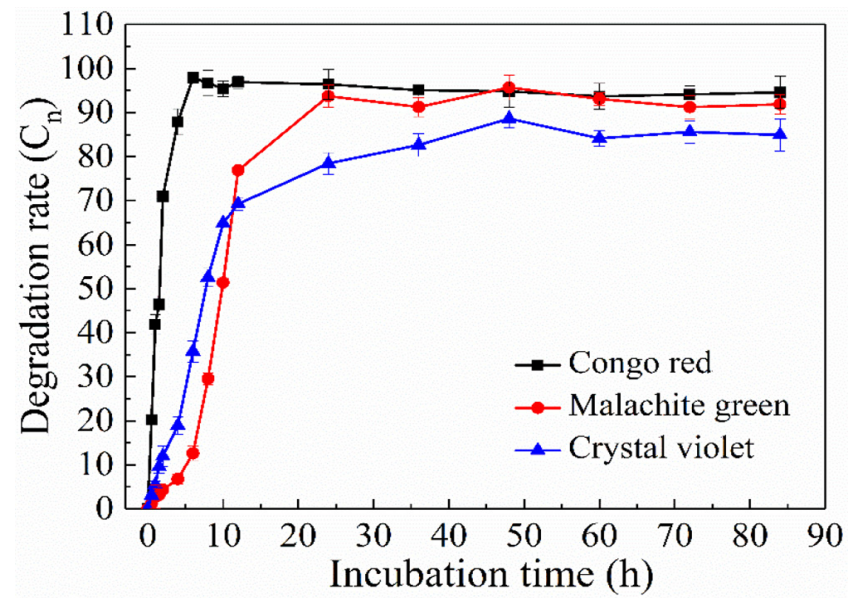

Fig. 7. Effect of incubation time on dye absorption. (The experiment conditions were as follows: $160 \mathrm{r} / \mathrm{min}$ and $28^{\circ} \mathrm{C}$. Sampled at an interval of $0.5 \mathrm{~h}$ ). first $6 \mathrm{~h}$ [34], reached the highest as 97.92\%. The adsorption equilibrium of malachite green and crystal violet can be easily reached within $24 \mathrm{~h}$ and $48 \mathrm{~h}$ respectively with a decolorization rate of $61 \%$ and $88.63 \%$. The results showed that the combined mycelial pellets GX-1310 had good decolorization effect on all three dyes in a short time.

\section{Conclusions}

It can be seen from the above results that the composite mycelium pellets constructed in this study can not only treat heavy metal ion wastewater and dye wastewater, but also treat papermaking wastewater. As there are many research reports on the adsorption of dye wastewater and heavy metal ion wastewater by biological bacteria, these have been explained in the introduction. However, there are few previous studies on the fixation of bacteria (X10-1-2) by fungi (G-13) to form composite mycelium pellets and the treatment of papermaking wastewater, we are the first to study this. The results showed that the composite mycelium pellets could degrade papermaking wastewater efficiently. In addition, the composite mycelium pellets can be considered as a new and effective two-strain system capable of removing multiple pollutants, which can provide a new research direction for the removal of multiple pollutants by biological bacteria in the future.

Wastewater treatment by combined mycelial pellets showed a superior performance because of synergies effect on recombination process. The present study showed that two-species immobilized mycelia pellet GX-1310 could be reused to treat papermaking wastewater. As the degradation rate of lignin, cellulose and hemicellulose could maintain more than $20 \%$ even if after treating for the third process, which indicates that GX-1310 can be applied in continuous wastewater treatment process for a long-time activity maintenance. In addition, GX-1310 can also be tolerable to relatively high temperatures and strong basic systems. In the high-temperature environment, GX-1310 could maintain high activities during papermaking wastewater treatment process. GX-1310 also has favorable treatment effects on all these three types of wastewater. The rate of decolorization of dyes surpasses $70 \%$ even if when $\mathrm{pH}$ is 9 . Moreover, GX-1310 is biodegraded and bioabsorbed highly tolerant and efficacious, therefore which has comprehensive application in the fields of polluted water treatments.

\section{Acknowledgment}

This project supported by National Natural Science Foundation of China (No.21776054).

\section{Author Contributions}

G.W. (M.S. Student) and F.Q. (M.S. Student) conducted all the experiments. G.G.J. (M.S. Student) and L.J.D. (M.S. Student) prepared the manuscript. D.X. (Miss) checked the grammar of the article. Y.H. (Professor) performed data analysis and supported in the manuscript preparation. 


\section{References}

1. Zahrar A, Afzal K, Shahram S, Mohammad R, Ebrahimi S. Glucose oxidase effect on treatment of textile effluent containing reactive azo dyes by Phanerochaete chrysosporium. J. Chem. Technol. Biot. 2017;92:1721-1726.

2. Wang MX, Zhang QL, Yang SJ. A novel biosorbent formed of marine-derived Penicillium janthinellum mycelial pellets for removing dyes from dye-containing wastewater. Chem. Eng. J. 2015;259(1): 837-844.

3. Ahluwalia SS, Goyal D. Microbial and plant derived biomass for removal of heavy metals from wastewater. Bioresour. Technol. 2017;98(12):2243-2257.

4. Awoke G, Amare G, Siqing X. Halomonas sp. strain A55, a novel dye decolorizing bacterium from dye-uncontaminated Rift Valley Soda lake. Chemosphere 2018;206:59-69.

5. Domingues FC, Queiroz JA, Cabral JMS, Fonseca LP. The influence of culture conditions on mycelial structure and cellulase production by Trichoderma reesei Rut C-30. Enzyme Microb. Technol. 2000;26(5-6):394-401.

6. Ma F, Zhang S, Shan D, Gao M. Optimization of culturing conditions for mucedine Y3 pellet. J. Harbin Institute Technol. 2009;41(8):38-41.

7. Fujita M, Iwahori K, Yamakawa K. Pellet formation of fungi and its application to starch wastewater treatment. Water Sci. Technol. 1993;28(2):267-274.

8. Ding J, Chen BL, Zhu LZ. Biosorption and biodegradation of polycyclic aromatic hydrocarbons by Phanerochaete chrysosporium in aqueous solution. Chin. Sci. Bull. 2012;6:613-621.

9. Dong Y, Li L, Hu X, Wu C. Optimization of o-chlorophenol biodegradation by combined mycelial pellets using response surface methodology. Water Air Soil Pollut. 2017;228:431.

10. Huang JL, Long MN, Fu YJ. Studies on the biosorption and hydrogen production of Klebsiella oxytoca HP1. J. Xiamen Univ. (Nat. Sci.) 2005;44(5):710-713.

11. Fane TL, Xi Y, Yao DS. Study on biosorption of crystal violet by mycelial pellets of Aspergillus terreus M11. Chem. Bioeng. 2010;3:77-79.

12. Zhang S, Li A, Cui D, Yang J, Ma F. Performance of enhanced biological SBR process for aniline treatment by mycelial pellet as biomass carrier. Bioresour. Technol. 2011;102(6):4360-4365.

13. Louise DR, Geoffrey MG. Use of pelleted and immobilized yeast and fungal biomass for heavy metal and radionuclide recovery. J. Ind. Microbiol. Biotechnol. 1991;7(2):97-104.

14. Lin FY, Wang RP, Yi ZW, Lei KY, Chan ZH. Biosorption of heavy metals cadmium, chromium, copper by marine bacterium Lysinibacillus xylanilyticus strain JZ008. J Appli. Oceanogr. 2018;3;387-394.

15. Lin SH, Pan XM, Shi XL, et al. Screening and Identification of Soil Mycelial Pellets and Application of Immobilized Mycelium. Biotechnol. Bull. 2019;35:76-81.

16. Chen HY, Wang MX, Shen YB, Yao SJ. Optimization of Two-species Whole-cell Immobilization System Constructed with Marine-derived Fungi and Its Biological Degradation Ability. Chinese J. Chem. Eng. 2014;22(2):187-192.

17. Sathishkumar M, Murugesan GS, Ayyasamy PM, Swaminathan K, Lakshmanaperumalsamy P. Bioremediation of arsenic con- taminated groundwater by modified mycelial pellets of Aspergillus fumigatus. Bull. Environ. Contam. Toxicol. 2004;72: 617-624.

18. Ninomiya K, Takamatsu H, Onishi A, Takahashi K, Shimizu $\mathrm{N}$. Sonocatalytic-Fenton reaction for enhanced $\mathrm{OH}$ radical generation and its application to lignin degradation. Ultrason. Sonochem. 2013;20:1092-1097.

19. Belhaine A, Ghezzar MR, Abdelmalek F, Tayebi K, Ghomari A, Addou A. Removal of methylene blue dye from water by a spent bleaching earth biosorbent. Water Sci. Technol. 2016;74(11):2534-2534.

20. Zhang S, Li A, Cui D, Yang J, Ma F. Performance of enhanced biological SBR process for aniline treatment by mycelial pellet as biomass carrier. Bioresour. Technol. 2011;102(6):4360-4365.

21. Seh-Bardan BJ, Othman R, Abd Wahid S, Sadegh-Zadeh F, Husin A. Biosorption of Heavy Metals in Leachate Derived from Gold Mine Tailings Using Aspergillus fumigatus. CleanSoil, Air, Water. 2013;41(4):356-364.

22. Xiao JB, Hu YY. Desorption and Mechanism of Dye Adsorbed Growing Mycelia of Aspergillus fumigatus. Environ. Sci. Technol. 2008;5:18-21,41.

23. Feng L, Wei W, Chengcheng L, et al. Self-mediated $\mathrm{pH}$ changes in culture medium affecting biosorption and biomineralization of $\mathrm{Cd}^{2+}$ by Bacillus cereus Cd01. J Hazard. Mater. 2018;358:178-186.

24. Nath J, Ray L. Biosorption of Malachite green from aqueous solution by dry cells of Bacillus cereus M 116 (MTCC 5521). J. Environ. Chem. Eng. 2015;386-394.

25. Li N, Jin WY, Yang FL. Hydrolytic acidification via rumen microorganisms and aerobic MBR to reduce contaminants in pulping midcourse wastewater. Desalin. Water Treat. 2016;57: 4365-4370.

26. Guo W, Yan H, Pei L. Study on Immobilization Method of Two-species Mycelial Pellet for Degradation of Lignocellulose. J Harbin Univ. Sci. Techno. 2018;23(4):127-132.

27. Yoo RH, Kim JH, McCarty PL, Bae JH. Effect of temperature on the treatment of domestic wastewater with a staged anaerobic fluidized membrane bioreactor. Water Sci. Technol. 2014;69(6): 1145-1150.

28. Hossain K, Ismail N. Bioremediation and detoxification of pulp and paper mill effluent: A review. Res. J. Environ. Toxicol. 2015;9(3):113-134.

29. Yan H, Yang Q, Wang XG. Study on Production of Cellulase by Bacillus sp.X18 and X10-1-2. Chem. Ind. Forest. Prod. 2006;26(2):83-86.

30. Feng Q, Guo W, Yan H. Isolation and Screening of the Lignin-degrading Fungusand Optimization of the Mycelium Pellet Cultivation Conditions. J. Harbin Univ. Sci. Techno. 2019;1: 138-144.

32. Ha HC, Honda Y, Watanabe T, Kuwahara M. Production of manganese peroxidase by pellet culture of the lignin-degrading basidiomycete, Pleurotus ostreatus. Appl. Microbiol. Biot. 2011;55(6):704-711.

32. Gautam RK, Mudhoo A, Lofrano G, Chattopadhyaya MC. Biomass-derived biosorbents for metal ions sequestration: Adsorbent modification and activation methods and adsorbent regeneration. J. Environ. Chem. Eng. 2014;2(1):239-259. 
33. Pei Y, Wu X, Xu G, et al. Tannin-immobilized cellulose microspheres as effective adsorbents for removing cationic dye (Methylene Blue) from aqueous solution. J. Chem. Technol. Biot. 2017;92(6):12761284.
34. Batmaz R, Mohammed N, Zaman M, Minhas G, Berry RM, Tam KC. Cellulose nanocrystals as promising adsorbents for the removal of cationic dyes. Cellulose 2014;21:1655-1665. 